\title{
Match activities of top-class female soccer assistant referees in relation to the offside line
}

\author{
JAVIER MALLO, ANTONIO CALA, PABLO GONZÁLEZ, \& ENRIQUE NAVARRO \\ Faculty of Physical Activity and Sport Sciences, Polytechnic University of Madrid, Madrid, Spain
}

\begin{abstract}
The aim of this study was to examine the match activities of top-class female assistant referees (mean age 34.8 years, $s=3.5$; stature $1.64 \mathrm{~m}, s=0.05$; weight $58.1 \mathrm{~kg}, s=7.4$; body mass index $21.6 \mathrm{~kg} \cdot \mathrm{m}^{-2}, s=2.4$ ) in relation to the offside line. Computerized match analyses were performed on 14 top-class assistant referees during 10 matches (a total of 20 observations) from the 2006 Fédération Internationale de Football Association (FIFA) under-20 Women's World Championship held in Russia. In addition, the position of the second last defensive player of both teams was calculated throughout the matches to determine the distance from the assistant referee to the offside line. The total distance covered during a game was $5594 \mathrm{~m}(s=473)$, of which $27 \%$ was sideways movements $(1492 \mathrm{~m}, s=135)$. High-intensity activities $\left(>13 \mathrm{~km} \cdot \mathrm{h}^{-1}\right)$ accounted for $1999 \mathrm{~m}(s=371)$. Mean distance from the offside line during the entire match was $1.06 \mathrm{~m}$ $(s=0.26)$. Total distance covered, high-intensity activities, and distance from the offside line were not different $(P>0.05)$ between the two halves of the game or consecutive 15-min match periods. Our results show that: (1) the kinematic demands placed on top-class female assistant referees are similar to those of top-class male assistant refereeing except for the amount of high-intensity activities, and (2) assistant referees were able to maintain the distance from the offside line during the match, which suggests an ability to keep up with the pace of the play throughout the match.
\end{abstract}

Keywords: Association football, match analysis, distance covered, high-intensity exercise, referees

\section{Introduction}

The kinematic demands placed on male soccer assistant referees have been previously examined at different standards of competition (Krustrup, Mohr, \& Bangsbo, 2002; Krustrup et al., 2009; Mallo, Navarro, García-Aranda, Gilis, \& Helsen, 2008; Mallo, Navarro, García-Aranda, \& Helsen, 2009a). These studies have shown that during a match an assistant referee covers around $5.5-7.0 \mathrm{~km}$, of which high-intensity activities represent $15-30 \%$ of the total match distance. The activity profile of top-class assistant referees seems to be related to the level of competition. Mallo et al. (2009a) reported that assistant referees performed more high-intensity running when officiating high-standard senior matches than during youth (under-17) matches. Recent studies (Krustrup, Mohr, Ellingsgaard, \& Bangsbo, 2005; Mohr, Krustrup, Andersson, Kirkendall, \& Bangsbo, 2008) have investigated the physical match performance of female soccer players. However, to our knowledge, there is no information available about the match activities of female assistant referees during competition. In addition, it is unclear to what extent the sex of the players who take part in the game affect the physical requirements of assistant refereeing.

It is also uncertain if assistant referees experience fatigue in the final stages of a match and if the development of fatigue has an effect on the technical performance of these officials. Krustrup et al. (2002) revealed that assistant referees increased the peak distance to the offside line in the second halves of matches and had a reduced ability to perform sprints after compared with before a match, suggesting a greater inability to keep up with play. The Refereeing Department of the Féderation Internationale de Football Association (FIFA) encourages assistant referees to be as close as possible, on their sideline, to the position of the second last defender (the 
"offside line") to be able to judge precisely offside situations. It is possible that, if assistant referees develop fatigue in the course of the match, they would not be able to maintain the distance from the offside line and may show an increased risk to make incorrect decisions.

The aims of the present study were to examine (1) the match activities of top-class female assistant referees during the final round of an international FIFA women's tournament, and (2) the distance from the assistant referee to the offside line throughout the match.

\section{Methods}

\section{Participants}

Fourteen women assistant referees (mean age 34.8 years, $s=3.5$; stature $1.64 \mathrm{~m}, s=0.05$; weight 58.1 $\mathrm{kg}, s=7.4$; body mass index $21.6 \mathrm{~kg} \cdot \mathrm{m}^{2}, s=2.4$ ) participated in the study. All of them were listed as FIFA international assistant referees and had 5.8 years $(s=3.6)$ of experience refereeing internationally. Written consent was obtained from FIFA's Refereeing Department ethics committee and from all the assistant referees involved in the tournament.

\section{Match analysis}

Ten matches from the 2006 FIFA under-20 Women's World Championship held in Russia were filmed (a total of 20 assistant referees' observations) using three digital video cameras positioned in the grandstand of each ground. The video cameras covered the full pitch, including the sidelines. After the matches, the images were downloaded to a computer laptop. Computerized analysis of the films was carried out at a frame rate of $1 \mathrm{~Hz}$ and the vertical projection of the assistant referees' centre of mass was manually digitized throughout the match. At the same time, the position of the second last defender of both teams was also indicated in all the frames. In each and every offside situation indicated by the assistant referees, the positions of the assistant referee and that of the attacking and defending players were captured and digitized at a frame rate of $25 \mathrm{~Hz}$. After digitizing a six-point calibration system for each camera, two-dimensional DLTbased algorithms (Abdel-Aziz \& Karara, 1971) were used to calculate the positions of the sportsmen on the field. These data were smoothed using quintic-spline functions with the cross generalized validation procedure to evaluate the adjustment factor (Woltring, 1985). The horizontal distance between the assistant referee and the second last defender was calculated every second and expressed as "distance from the offside line". When the assistant referee was moving behind the defender's position, these distances were considered as negative values. In contrast, when the assistant referee was moving ahead of the second last defender, these distances were considered as positive values. Assistant referees ${ }^{6}$ match activities were calculated from the spline polynomial functions and coded into five categories (Mallo et al., 2008): (1) standing still $\left(<3.6 \mathrm{~km} \cdot \mathrm{h}^{1}\right)$, (2) walking $\left(3.61-7.20 \mathrm{~km} \cdot \mathrm{h}^{1}\right)$, (3) jogging $\left(7.21-13.0 \mathrm{~km} \cdot \mathrm{h}^{1}\right)$, (4) cruising $\left(13.01-18.0 \mathrm{~km} \cdot \mathrm{h}^{\mathrm{l}}\right.$ ), and (5) high-intensity running $\left(>18.01 \mathrm{~km} \cdot \mathrm{h}^{\mathbf{l}}\right)$. Exercise performed at speeds exceeding $13 \mathrm{~km} \cdot \mathrm{h}^{1}$ was considered "highintensity activity". Sidewards displacements were also taken into account for later analysis.

The validity and reliability of the results obtained by this match analysis technique has been previously determined. Mallo et al. $(2007,2008)$ reported that the root mean square error (Allard, Blanchi, \& Aissaqui, 1995) when reconstructing the coordinates in the $\mathrm{x}$ - and $\mathrm{y}$-axis was 0.23 and $0.17 \mathrm{~m}$, respectively. The root mean square error for reconstructing the distance between two positions was less than $2 \%$. Calculation of the bias and $95 \%$ limits of agreement (Bland \& Altman, 1986) gave a value of $0.02 \mathrm{~m}(s=0.74)$. No statistically significant differences $(P>0.05)$ were detected in the intra- and inter-rater reliability tests, with total differences in the kinematic data always being less than $1 \%$ (Mallo et al., 2007, 2008).

\section{Data analysis}

Results are presented as means and standard deviations $(s)$. Differences between the first and second halves were assessed using paired $t$-tests. Analysis of variance (ANOVA) was used to test for differences between the total distance covered, high-intensity activities, and distance from the offside line over successive 15-min periods of match play. For the analysis of match activities between halves, a twoway ANOVA was performed using a 5 (activity category: standing still, walking, jogging, cruising, high-speed running) $\times 2$ (period: first half, second half) design with repeated measures on both factors. A two-way ANOVA was also carried out on the mean distance and time spent moving ahead and behind the offside line, using a 2 (assistant referees ' position in relation to the offside line: ahead, behind) $\times 6$ (match periods: $0-15,16-30,31-45,46-60,61-75$, 76-90) design with repeated measures. All the repeated-measures ANOVAs were carried out after ensuring the sphericity assumption was not violated. The Geisser-Greenhouse correction was used to adjust the degrees of freedom when epsilon was less than 0.75 (Thomas \& Nelson, 2001). Post-hoc analyses were performed using a Newman-Keuls 
test. The meaningfulness of the difference between two means was determined by the effect size: (mean 1-mean2) $\cdot \mathrm{s}^{1}$ (Cohen, 1969, in Thomas \& Nelson, 2001). The $95 \%$ confidence intervals (CI) were also determined. Statistical significance was set at $P<$ 0.05 .

\section{Results}

\section{Match distance}

Mean distance covered during a match was $5594 \mathrm{~m}$ $(s=473)$ and decreased $115 \mathrm{~m}$ between halves $(P=$ 0.30 ; effect size: $0.34 ; 95 \% \mathrm{CI}:-846$ to $1077 \mathrm{~m}$ ) from $2855 \mathrm{~m}(s=324)$ in the first half to $2739 \mathrm{~m}$ $(s=356)$ in the second half. The peak distance covered was achieved in the first $15 \mathrm{~min}$ of the game (1021 $\mathrm{m}, s=143)$ when assistant referees travelled $11 \%$ further than in the last $15 \min (912$ $\mathrm{m}, s=163$; effect size: 0.71 ). Sidewards movements represented $26.6 \%, s=5.1(1492 \mathrm{~m}, s=135)$ of total match distance without no difference between halves ( $P=0.37$; effect size: $0.36 ; 95 \% \mathrm{CI}:-241$ to $298 \mathrm{~m}$ ) or 15 -min match periods ( $P$ at best 0.13 )

\section{Match activities}

Table I shows the distances covered by the assistant referees at different speeds. There was no interaction between the distance covered at different speeds during the two halves of the match $\left(F_{2,32}=0.35 ; P=\right.$ $0.67)$.

On average, the assistant referees stood for $53.5 \%$ $(s=3.2)$, walked for $20.5 \%(s=2.7)$, jogged for $15.4 \%(s=1.6)$, cruised for $6.4 \%(s=1.0)$, and ran at high intensity for $4.2 \%(s=1.2)$ of the total playing time. There was no activity category $\times$ period interaction $\left(F_{2,30}=0.97 ; P=0.37\right)$.

The assistant referees spent $572 \mathrm{~s} \quad(s=100)$ performing high-intensity activities, with no difference between the first ( $295 \mathrm{~s}, s=76)$ and second half $(278 \mathrm{~s}, s=104)$ of the match $(P=0.63$; effect size: $0.19 ; 95 \%$ CI: -282 to 315 s). Time spent exercising at a high intensity was not different $(P$ at best 0.18 ; effect size at best 0.49 ) between 15 -min match periods.

Table I. Distance covered $(\mathrm{m})$ at different speeds during both halves of a match (mean $\pm s$ )

\begin{tabular}{lrrr}
\hline & First half & Second half & \multicolumn{1}{c}{ Overall } \\
\hline Standing still & $420 \pm 94$ & $438 \pm 121$ & $858 \pm 149$ \\
Walking & $586 \pm 101$ & $586 \pm 155$ & $1172 \pm 180$ \\
Jogging & $811 \pm 106$ & $754 \pm 135$ & $1565 \pm 179$ \\
Cruising & $526 \pm 108$ & $490 \pm 137$ & $1016 \pm 149$ \\
High-speed running & $512 \pm 204$ & $471 \pm 252$ & $983 \pm 274$ \\
Total & $2855 \pm 324$ & $2739 \pm 356$ & $5594 \pm 473$ \\
\hline
\end{tabular}

\section{Distance from offside situations}

Thirty-two offside situations indicated by the assistant referees during the matches were replayed for further analysis. Mean distance to the second last defender in these situations was $0.66 \mathrm{~m}(s=0.61)$, with no difference between halves (first half: $0.69 \mathrm{~m}$, $s=0.73$; second half: $0.62 \mathrm{~m}, s=0.45)(P=0.77$; effect size: 0.11 ).

\section{Distance from the offside line}

Mean distance from the offside line throughout the match was $1.06 \mathrm{~m}(s=0.26)$, with a decrease from $1.07 \mathrm{~m}(s=0.34)$ to $1.06 \mathrm{~m}(s=0.16)(P=0.90$; effect size: 0.04$)$ from the first to the second half. There was no difference ( $P$ at best 0.28 ; effect size at best 0.33 ) in distance from the offside line between 15-min periods during the game (Figure 1).

No difference $(P=0.35$; effect size: 0.19$)$ was observed between the mean distance moved ahead $(1.03 \mathrm{~m}, s=0.20)$ or behind $(-1.07 \mathrm{~m}, s=0.22)$ the offside line by the assistant referees during the two halves of the match. This distance was not different ( $P$ at best 0.07 ; effect size at best 0.27 ) between 15min match intervals either (Figure 2). On average, assistant referees moved ahead of the offside line for $48.6 \%(s=15.1)$ of total match time, while for the remaining $51.4 \%(s=15.3)$ they moved behind the second-last defender. No differences were detected in time spent moving ahead and behind the offside line throughout 45 - or 15 -min periods $(P$ at best 0.45 ; effect size at best 0.35 ) (Figure 3 ).

\section{Discussion}

The major findings of the present study are that: (1) top-class female assistant referees cover around $5.5 \mathrm{~km}$ during a competitive soccer match, with almost $2 \mathrm{~km}$ of this distance running at speeds exceeding $13 \mathrm{~km} \cdot \mathrm{h}^{1}$, and (2) the assistant referees" physical performance was not reduced in the second half of the game, as distance covered, high-intensity activities, distance from offside situations, and distance from the offside line were not different from first half values. Specifically, the fact that the distance from the offside line was not different between 15-min match periods suggests that assistant referees were able to keep up with the pace of the game imposed by the players.

The aim of this study was to examine the match activities performed by top-class female soccer assistant referees. Total distance covered during a match ranged from 5 to $6.9 \mathrm{~km}$. This value is very similar to that previously reported for top-class male assistant referees when officiating youth and senior competitive matches (Mallo et al., 2008, 2009a) and 

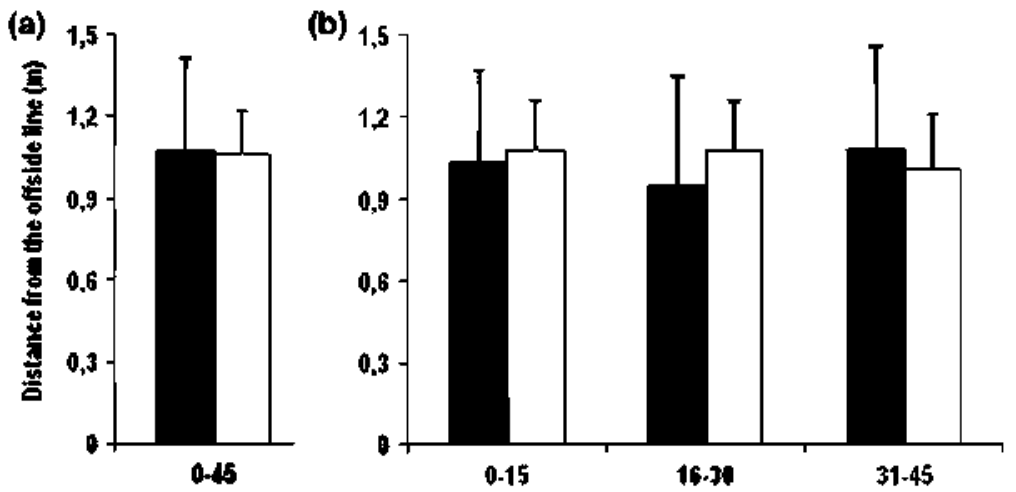

Figure 1. Mean distance from the oftêside line (m) for (a) 45- and (b) 15-min match periods.

slightly below that reported by Krustrup et al. (2002, 2009). The movement pattern of the assistant referees remains fairly constant when officiating men's and women's soccer matches, especially in terms of the amount of low-intensity $(<7.2 \mathrm{~km}$. $\left.\mathrm{h}^{\mathrm{l}}\right)$ and medium-intensity $\left(7.21-13.0 \mathrm{~km} \cdot \mathrm{h}{ }^{\mathrm{l}}\right) \mathrm{ac}-$ tivities and sideways movements (Mallo et al., 2008, $2009 \mathrm{a})$. Interestingly, the amount of intense exercise seems to be related to the standard of competition, as the assistant referees that took part in the FIFA Confederations Cup 2005 (high-standard men's tournament; Mallo et al., 2009a) ran at high-speeds $6 \%$ further than the assistant referees observed in the present study. These data support previous observations of female (Mohr et al., 2008) and male players (Bangsbo, Norregaard, \& Thorso, 1991; Mohr, Krustrup, \& Bangsbo, 2003) and referees (Castagna \& Abt, 2003; Castagna, Abt, \& D'Ottavio, 2004; Krustrup \& Bangsbo, 2001; Mallo, Navarro, GarciaAranda, \& Helsen, 2009b), suggesting that the amount of high-intensity running is related to the level of competition. The between-sex difference in the production of intense exercise is crucial if female assistant referees are required to officiate men's competitive games. In a recent study (Mujika, Santisteban, Impellizzeri, \& Castagna, 2009), it was revealed that elite male footballers covered $97 \%$ more distance during the Yo-Yo

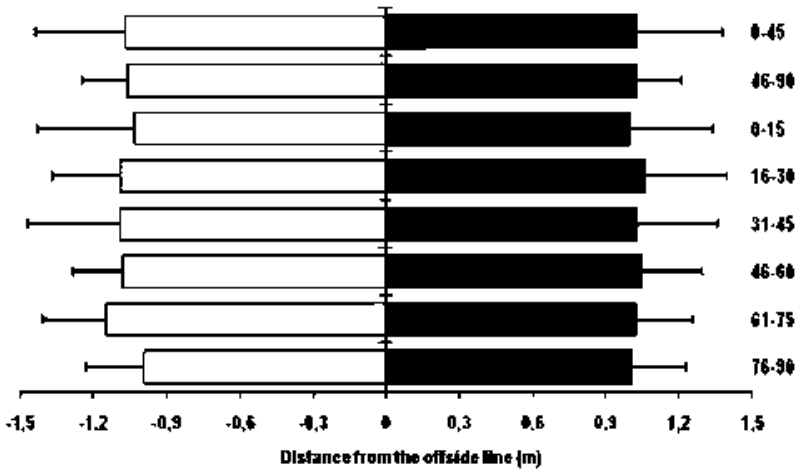

Figure 2. Mean distance (m) moving ahead $(+)$ and behind $(-)$ the offside line for 45- and 15-min match periods. intermittent recovery test than their female counterparts. For this reason, it is essential that female officials undertake specific high-intensity intermittent training sessions to improve their physical capacity to fulfil the demands of male refereeing. Furthermore, to follow the offside line, assistant referees perform a lot of sideways movements that require specific neuromuscular training, as they usually begin and finish their high-intensity activities with a quick $90^{\circ}$ turn so as to be constantly facing the play.

The development of fatigue towards the end of a match by referees and assistant referees is a controversial topic. Recent investigations have shown that the officials' exercise intensity is related to the movement activities of the players (Weston, Castagna, Impellizzeri, Rampinini, \& Abt, 2007) and the way the players move the ball (Mallo et al., 2009a, $2009 \mathrm{~b}$ ). Top-class female players cover $9-11 \mathrm{~km}$ during competition, of which $1.7 \mathrm{~km}$ represent high-intensity running, and experience a $25-57 \%$ decline in the amount of high-intensity activities performed in the last $15 \mathrm{~min}$ of a match (Mohr et al., 2008). In addition, high-intensity running performed by male players was also $35-45 \%$ lower in the last $15 \mathrm{~min}$ than in the first $15 \mathrm{~min}$ of the game (Mohr et al., 2003). Furthermore, several studies have reported an impairment of physical performance in the second half of games, as the total

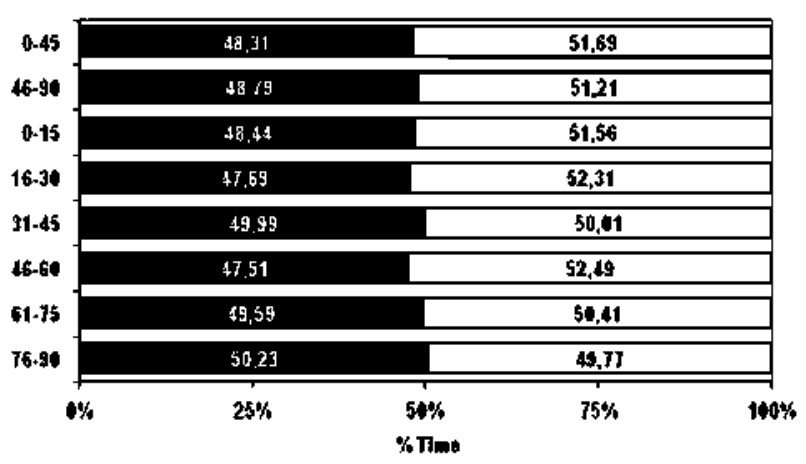

Figure 3. Time (\%) spent moving ahead and behind the offside line for 45- and 15-min match periods. 
distances covered and/or the number of highzintensity activities were reduced in relation to the first half both for referees (Catterall, Reilly, Atkinson, \& Goldwells, 1993; D'Ottavio \& Castagna, 2001; Mallo et al., 2007) and assistant referees (Krustrup et al., 2002; Mallo et al., 2008). However, in the present study we did not detect differences in kinematics between halves, in line with other studies of referees (Krustrup \& Bangsbo, 2001; Mallo et al., $2009 \mathrm{~b}$ ) and assistant referees (Krustrup et al., 2009; Mallo et al., 2009a). Specifically, all the betweenhalf comparisons (distance covered, sidewards movements, high-intensity activities, distance from offside situations, and distance from the offside line) revealed small effect sizes, from 0.04 to 0.36 at the most. Based on all of the above, it would appear that the development of fatigue by officials appears to be related to the tempo of the play imposed by the players. If top-class female players develop fatigue in the last stages of the match (Mohr et al., 2008), then the tempo of the game would be lowered in the final minutes and the assistant referees would be able to follow the pace of the game, which could explain the fact the assistant referees covered the most distance in the first $15 \mathrm{~min}$ of matches. In line with this, a higher physical capacity (Castagna, Abt, \& D’Ottavio, 2005; Krustrup \& Bangsbo, 2001) developed through specific high-intensity training sessions (Weston, Helsen, MacMahon, \& Kirkendall, 2004) would also help to improve the kinematic performance of the officials.

Assistant referees play a supporting role to the referee during games to judge offside situations. For this reason, they need to move perpendicular to the second last defender of each team to have an optimal view of the pitch. During the current tournament, mean distance from the offside line was $1.06 \mathrm{~m}$, which is lower than that calculated by Krustrup et al. (2002) for Danish male assistant referees $(2 \mathrm{~m})$. To determine whether the development of fatigue had an effect on the technical positioning of the assistant referees, we examined the distance from the official to the offside line throughout the match. As can be seen from Figure 1, assistant referees were able to keep this distance over the successive 15-min periods, suggesting that they could cope with the kinematic demands of the game. Furthermore, assistant referees were moving ahead and behind the offside line almost at the same mean distance (Figure 2) and for a similar proportion of total playing time (Figure 3). To our knowledge, this is the first time that such values have been calculated, which should be useful in evaluating the quality of the technical positioning of assistant referees and their ability to keep pace with the game. If assistant referees experience fatigue in the last stages of the match, then the distance to the offside line should increase in the final 15-min period. Interestingly, assistant referees reduced the distance from the offside line by $40 \mathrm{~cm}$ when indicating the offside situations. It is possible that when assistant referees detected a conflicting position, they reduced the distance from the second last defender to gain a better perspective of the play. Nevertheless, the distance from the offside situations ranged from 0.05 to $2.45 \mathrm{~m}$, which suggests that in some cases the assistant referees were far away from the offside line and had to make a decision from a less than ideal position. It remains a challenge to evaluate how the positioning in the field of play affects the correctness of the decisions taken by the assistant referees when judging offsides. For this reason, it is essential to determine the parameters that help to improve the decision-making process of assistant referees in these situations (Gilis, Helsen, Catteeuw, \& Wagemans, 2008; Helsen \& Bultynck, 2004; Helsen, Gilis, \& Weston, 2006), where they have to simultaneously perceive the positions of the ball, the attacker, and the second last defender and take the correct technical decision in a fraction of a second.

In summary, we found that the demands placed on top-class female assistant referees are similar to those faced by male assistant referees except for the amount of high-intensity activities. The women assistant referees were able to cope with the kinematic demands of the game imposed by top-class under- 20 women players as they kept up with the offside line throughout the match.

\section{Acknowledgements}

This study was supported by the Refereeing Department of the Fédération Internationale de Football Association. We also acknowledge the cooperation of Jose María Garcia-Aranda.

\section{References}

Abdel-Aziz, Y. I, \& Karara, H. M. (1971). Direct linear transformation from comparator coordinates into space coordinates in close range photogrammetry. In The American Society of Photogrammetry (Ed.), Procedings of the Sympositm on Close Range Photogrammetry (pp, 1-18). Falls Church, VA: ASP.

Allard, P., Blanchi, J. P., \& Aïssaqui, R. (1995). Bases of threedimensional reconstruction. In P. Allard, I. A. F. Stokes, \& J. P. Bianchi (Eds.), Three-dimensional analysis of htman movement (pp. 19-40). Champaign, $\Pi$ : Human Kinetics.

Bangsbo, J., Norregaard, L., \& Thorso, F. (1991). Activity profile of competition soccer. Canadian fournal of Sports Science, 16, 110-116.

Bland, J. M., \& Altman, D. G. (1986). Statistical methods for assessing agreement between two methods of clinical measurement. The Lancet, I, 307-310. 
Castagna, C., \& Abt, G. (2003). Intermatch variation of match activity in elite Italian soccer referees. Fournal of Strength and Conditioning Research, 17, 388-392.

Castagna, C., Abt, G., \& D'Ottavio, S. (2004). Activity profile of international-level soccer referees during competitive matches. Journal of Strength and Conditioning Research, 18, 486-490.

Castagna, C., Abt, G., \& D'Ottavio, S. (2005). Competitive-level differences in Yo-Yo intermittent recovery and twelve minute run test performance in soccer referees. Fournal of Strength and Conditioning Restarch, 19, 805-809.

Catterall, C., Reilly, T., Atkinson, G., \& Goldwells, A. (1993). Analysis of work rates and heart rates of association football referees. British Fournal of Sports Medicine, 27, 193-196.

D'Ottavio, S., \& Castagna, C. (2001). Physiological load imposed on elite soccer referees during actual match play. Fournal of Sports Medicine and Physical Fitness, 41, 27-32.

Gilis, B., Helsen, W, Catteeuw, P., \& Wagemans, J. (2008). Offiside decisions by expert assistant referees in association football: Perception and recall of spatial positions in complex dynamic events. Fournal of Experimental Psychology: Applied, 14, 21-35.

Helsen, W. F., \& Bultynck, J. B. (2004). Physical and perceptualcognitive demands of top-class refereeing in association football. Fournal of Sports Sciences, 22, 179-189.

Helsen, W., Gilis, B., \& Weston, M. (2006). Errors in judging "offside" in association football: Test of the optical error versus the perceptual flash-lag hypothesis. Fournal of Sports Sciences, $24,521-528$.

Krustrup, P., \& Bangsbo, J. (2001). Physiological demands of topclass soccer refereeing in relation to physical capacity: Effect of intense intermittent exercise training. Fournal of Sports Sciences, $19,881-891$

Krustrup, P., Helsen, W, Randers, M. B., Christensen, J. F, MacDonald, C., Rebelo, A. N., et al. (2009). Activity profile and physical demands of football referees and assistant referees in international games. Yottrnal of Sports Sciences, 27, $1167-1176$.

Krustrup, P., Mohr, M., \& Bangsbo. (2002). Activity profile and physiological demands of top-class soccer assistant refereeing in relation to training status. Fournal of Sports Sciences, 20, $861-871$.

Krustrup, P., Mohr, M., Ellingsgaard, H., \& Bangsbo, J. (2005). Physical demands during an elite female soccer game: Im- portance of training status. Medicine and Science in Sports and Exerctse, 37, 1242-1248.

Mallo, J., Navarro, E., García-Aranda, J. M., Gilis, B., \& Helsen, W. (2007). Activity protile of top-class soccer referees in relation to performance in selected physical tests. Fournal of Sports Sciences, 25, 805-813.

Mallo, J., Navarro, E., García-Aranda, J. M., Gilis, B., \& Helsen, W. (2008). Analysis of the kinematical demands imposed on top-class assistant referees during competitive soccer matches. Gottrnal of Strength and Conditioning Research, 22, 235-242.

Mallo, J., Navarro, E., García-Aranda, J. M., \& Helsen, W. (2009a). Physical demands of top-class soccer assistant refereeing during high-standard matches. Intemational foumal of Sports Medicine, 30, 331-336.

Mallo, J., Navarro, E., García-Aranda, J. M., \& Helsen, W. $(2009 \mathrm{~b})$. Activity profile of top-class association football referees in relation to finess-test performance and match standard. Jotrnal of Sports Sciences, 27, 9-17.

Mohr, M., Krustrup, P., Andersson, H., Kirkendall, D., \& Bangsbo, J. (2008). Match activities of elite women soccer players at different performance levels. Fournal of Strength and Conditioning Rescarch, 22, 341-349.

Mohr, M., Krustrup, P., \& Bangsbo, J. (2003). Match performance of high-standard soccer players with special reference to development of fatigue. Yournal of Sports Sciences, 21, 519-528.

Mujika, I., Santisteban, J., Impellizzeri, F. M., \& Castagna, C. (2009). Fitness determinants of success in men's and women's football. Fournal of Sports Sciences, 27, 107-114.

Thomas, J. R., \& Nelson, J. K. (2001). Research methods in physical activity. Champaign, IL: Human Kinetics.

Weston, M., Castagna, C., Impellizzeri, F. M., Rampinini, E., \& Abt, G. (2007). Analysis of physical match performance in English Premier League soccer referees with particular reference to first half and player work rates. Fournal of Science and Medicine in Sport, 10, 390-397.

Weston, M., Helsen, W. F., MacMahon, C., \& Kirkendall, D. (2004). The impact of specific high intensity training sessions upon football referees' finess levels. American fournal of Sports Medicine, 32 (suppl), 54S-61S.

Woltring, H. J. (1985). On optimal smoothing and deritate estimation from noisy displacement data in biomechanics. Human Movement Sciences, 4, 229-245. 